\title{
Take-Home Naloxone and the Prevention of Deaths from Heroin Overdose: Pursuing Strong Science, Fuller Understanding, Greater Impact
}

\author{
John Strang \\ National Addiction Centre, Kings College London, London, UK
}

\author{
Keywords \\ Harm reduction - Heroin - Naloxone - Overdose - Deaths . \\ Prevention - Opioid - Opiate
}

\begin{abstract}
Background and Context: Realization of the life-saving potential of "take-home naloxone" has been a personal journey, but it has also been a collective journey. It has been a story of individual exploration and growth, and also a story of changes at a societal level. "Take-home naloxone" has matured since its first conceptualization a quarter of a century ago. It required recognition of the enormous burden of deaths from drug overdose (particularly heroin and other opioids), and also realization of critical clusterings (such as post-release from prison). It also required realization that, since many overdose deaths are witnessed, we can potentially prevent many deaths by mobilizing drug users themselves, their families, and the wider caring community to act as intervention workforce to give life-saving interim emergency care. Summary of Scope: This article explores 5 areas (many illustrations UK-based where the author works): first$l y$, the need for strong science; secondly, our improved understanding of opioid overdose and deaths; thirdly, the
\end{abstract}

karger@karger.com www.karger.com/ear

Karger $\stackrel{\text { ' }}{5}$

BOPEN ACCESS
C 2021 The Author(s).

Published by S. Karger AG, Basel

This article is licensed under the Creative Commons Attribution 4.0 International License (CC BY) (http://www.karger.com/Services/ OpenAccessLicense). Usage, derivative works and distribution are permitted provided that proper credit is given to the author and the original publisher. search for greater impact from our policies and interventions; fourthly, developing better forms of naloxone; and fifthly, examining the challenges still to be addressed. Key Messages: "Take-home naloxone" is an exemplar of harm reduction with potential global impact - drug policy and practice for the public good. However, "having the potential" is not good enough - there needs to be actual implementation. This will be easier once the component parts of "take-home naloxone" are improved (better naloxone products, better training aids, revised legislation, and explicit funding support). Many improvements are already possible, but we hesitate about implementation. It is our responsibility to drive progress faster. With "take-home naloxone," we can be proud of what we have achieved, but we must also be humble about how much more we still need to do.

(C) 2021 The Author(s).

Published by S. Karger AG, Basel

\section{Introduction}

"No man is an island, entire of itself; every man is a piece of the continent, a part of the main; if a clod be washed away by the sea, Europe is the less" (John Donne, Devo-
Correspondence to:

John Strang, john.strang@kcl.ac.uk 


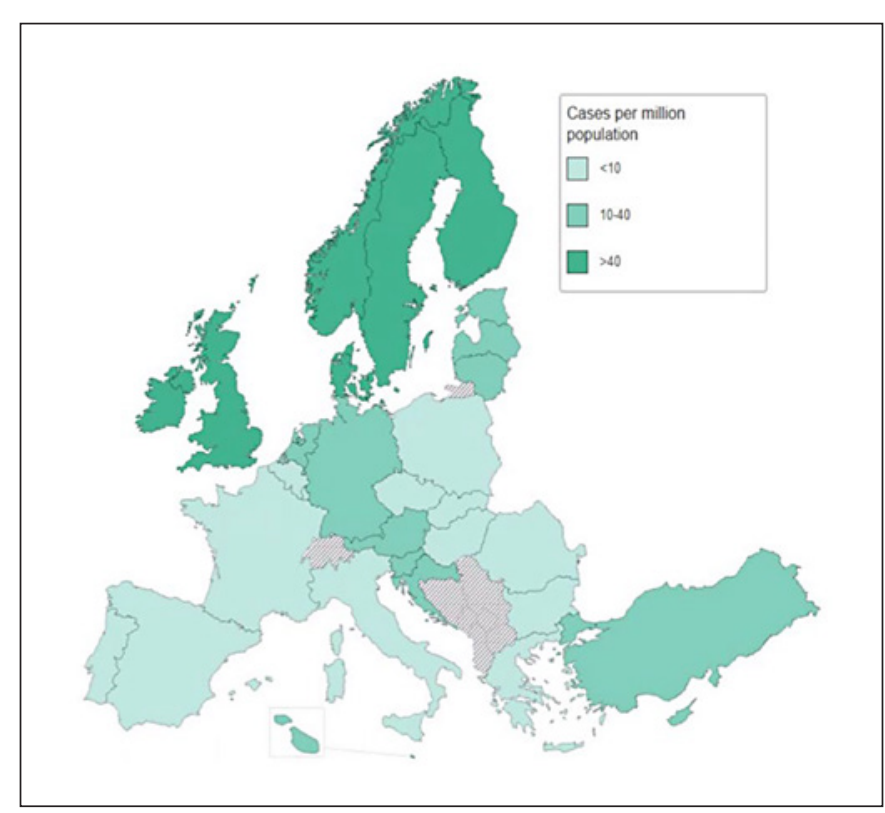

Fig. 1. Drug-related deaths across Europe (2019).

tions, 1624). John Donne goes on to say: “Any man's death diminishes me, because I am involved in mankind: and therefore never send to know for whom the bell tolls, it tolls for thee." None of us lives in isolation: our problems may be personal, family, or societal but they are problems we must address collectively. Our contributions through treatment, policy, or research are shared contributions none of our product is exclusive to our own contribution.

I owe a debt of gratitude to many. This includes colleagues in research, in clinical practice, and in public policy with whom the concepts and initiatives described in this article have been tested and implemented. My thinking and the associated works have also been influenced significantly by individuals who themselves use drugs plus their family and peers.

Over the last quarter of a century, the enormous burden of deaths from heroin overdose (and other opioids, particularly in recent years) has increased. We now understand better the critical clusterings of overdose events (in time, in context, and in person) and have developed interventions to prevent opioid overdose deaths.

North America is severely afflicted, with overlapping epidemics. Annual deaths from prescription opioids have quadrupled over the last couple of decades plus, more recently, heroin deaths quadrupling over the last decade, as well as a recent explosion in deaths involving fentanyl and analogues (mostly illicitly manufactured) [1]. Europe has a variable problem [2], with some countries such as Scot- land severely afflicted, and nearly 9,000 European citizens dying annually of opioid overdose (strangely higher in northern Europe) (Fig. 1).

In addition to studying overdose deaths, we need to consider if there are opportunities to intervene - either to prevent the occurrence of overdose and/or to prevent the fatal outcome. In much the same way as with other lifesaving emergency interventions (such as EpiPen and the interim emergency treatment of anaphylaxis, or cardiopulmonary resuscitation for the interim management of heart attack and, even further, public placement of cardiac defibrillators), we need to consider similar technology transfer of rescue breathing and naloxone, extending it from the emergency room into the public arena.

The structure of this article is that there is an opening section that explores the need for strong science, then a second section takes stock of our understanding of opioid overdose and deaths, followed by a third section that examines efforts to improve policies and interventions, then a fourth section describes potentially better forms of naloxone, and finally, a fifth section considers the challenges still to be addressed.

\section{The Contribution of Science}

Well-conceived and competently conducted research is particularly important for problems which has historically received only moderate attention and which involve individuals who are largely disenfranchised (and particularly overlooked at times of austerity and crisis). We need to look at the quality of science, as well as the volume.

We need better understanding of the influences upon risk of overdose and risk of overdose death. With other health conditions and behaviours, we would look for public health and individual treatment and preventive responses: we must do the same to prevent drug overdose deaths.

We can already describe the situations with greatest risk. We can identify individuals or patterns which are associated with greater danger of overdose death - a former-heroin user resuming heroin use (even an impulsive single occasion) after loss of tolerance, using alone, using by injection (especially intravenously), concurrent use of sedative drugs (alcohol and benzodiazepines), the emergence of illicit fentanyl of variable purity. Each element increases the dangerousness.

Treatment protects. For individuals caught up in dependent patterns of heroin/opioid use, we have treatments of proven effectiveness, e.g., methadone or bu- 


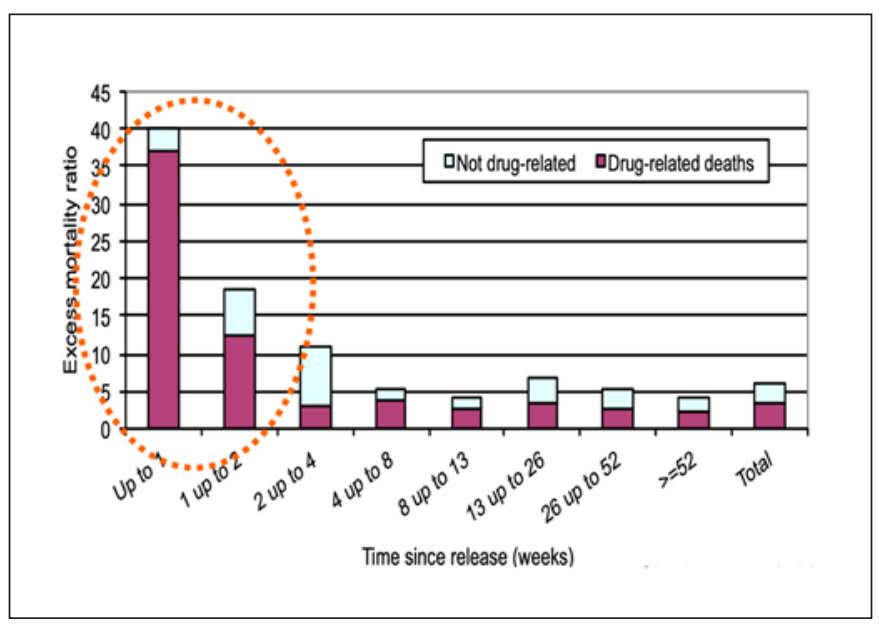

Fig. 2. Graph of deaths post-release from prison (England \& Wales, 1999).

prenorphine which substantially reduce risk of drug overdose death [3-7]. However, the interplay with treatment is complex and can occasionally result in inadvertent harm. Risk of overdose is not constant. For example, there is a transient initial increase in risk of overdose death during the first weeks of methadone treatment [8$10]$, probably when the new opioid medication is taken alongside continued use of heroin or other drugs. A concentration of risk occurs when terminating opiate substitution treatments [11-14], particularly in the next month $[8,10]$. There are also settings of particular hazard, as evidenced by the concentration of overdose deaths in the days following release from prison $[15,16]$ and similarly following discharge from hospital or residential rehabilitation [17-19]. This is clearly evident in deaths after prison release across England and Wales [15, 20], with excess mortality over the whole year, but with intense concentration of drug-related deaths in the first 2 weeks (Fig. 2).

We have also gained better understanding through interviews with drug users themselves, investigating not only the frequency and nature of personal overdoses but also the extent to which they have witnessed the overdoses of others. We learn that overdoses occur usually in the presence of others, with at least half of respondents having already experienced a serious drug overdose themselves, and with an ever larger proportion having observed overdose events amongst others [21-24]. With this knowledge, might drug users themselves constitute an overlooked untapped emergency intervention workforce, if we train them and provide them with naloxone $[22,25,26]$ ?

Take-Home Naloxone and the Prevention of Heroin Overdose Deaths

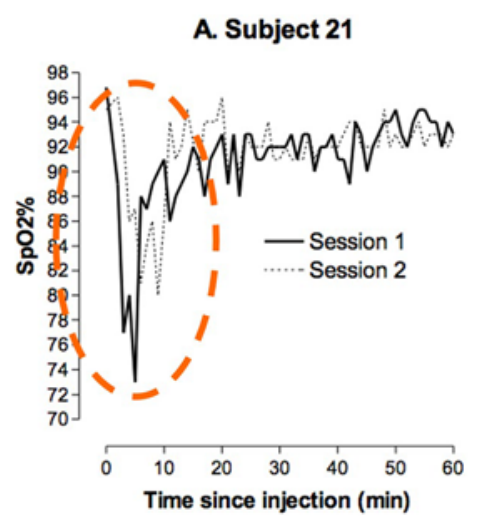

Fig. 3. Graph of case study of intravenous diamorphine and $\mathrm{SpO} 2$ (regular dose).

Scientific methods used should include, where both ethics and practicalities permit, randomized clinical trials as well as methods such as time-series analyses [27-30]. Such studies have contributed to a fuller stronger scientific basis for "take-home naloxone" which previously was a classic example of "undone science" [31].

\section{Fuller Understanding}

We need to understand more about what actually happens during heroin overdose, and why death occurs. Heroin is disproportionately highly represented in data on drug-related deaths (when compared with non-opioid overdose). Opiates are respiratory depressants, especially heroin. A pharmacological effect of opiates is to downregulate the feedback loop activity in the lung-brain axis: breathing becomes shallow and slows. This occurs within minutes after intravenous injection (Fig. 3). This is a crucial feature of the respiratory depression that occurs after heroin use - with the breathing of the overdose victim becoming shallow or absent, as if they have forgotten to breathe.

Previous study identified lowering of blood oxygen levels (hypoxaemia; low SpO2) in the immediate postdose period amongst patients receiving long-term diamorphine (heroin) maintenance [32]. More intense experiments were a necessary next step in study of heroin overdose. A laboratory model of overdose was required.

In the UK, pharmaceutical heroin (diamorphine) was once prescribed as maintenance treatment for addic- 

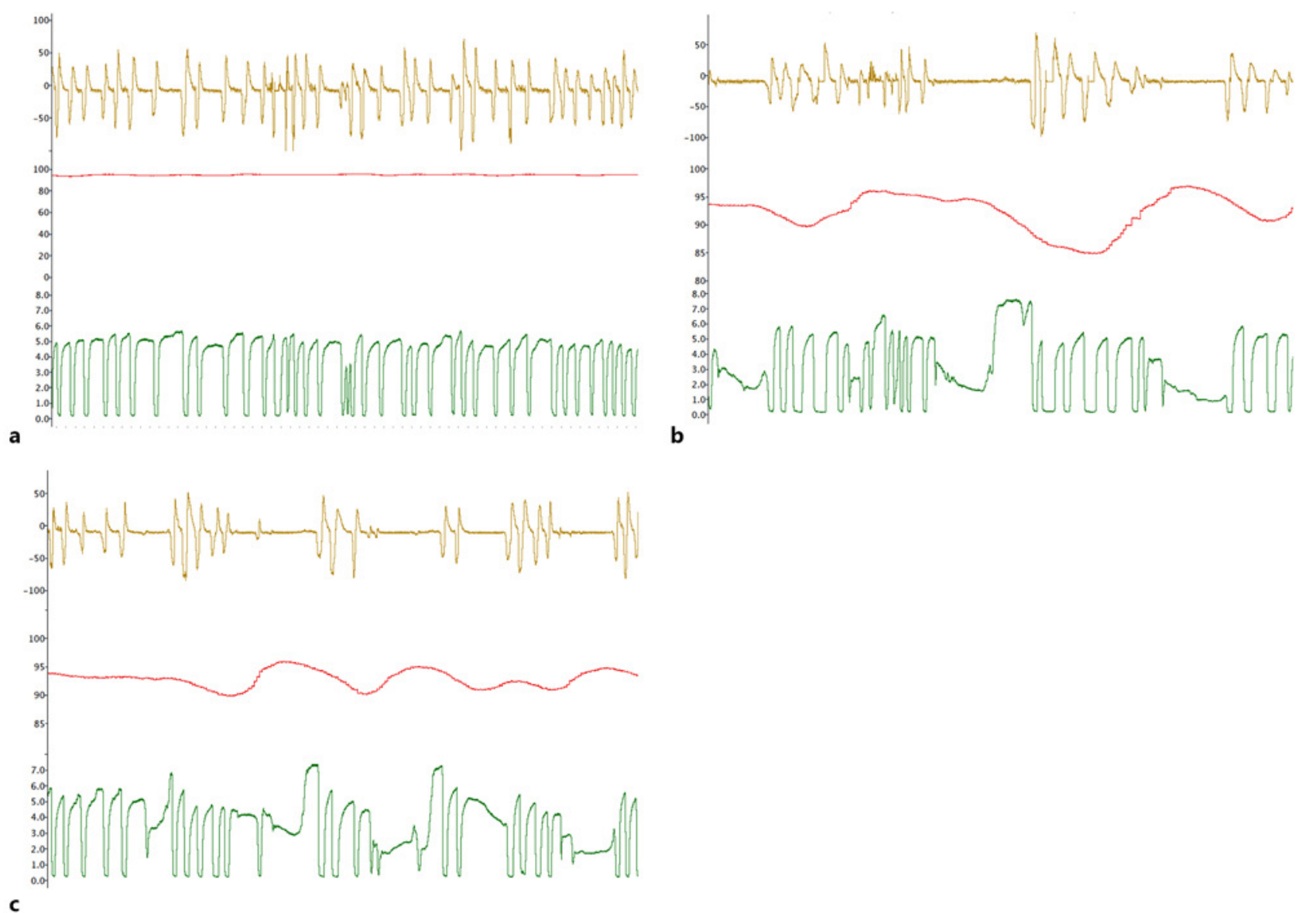

Fig. 4. a-c Graphs of acute onset apnoea after intravenous diamorphine (regular dose).

tion - historically called the "British System" [33]. A small number of patients remain on this treatment, self-administering their prescribed dose. Approval was obtained to invite some of these patients to allow clinical and physiological measurement whilst they self-injected their daily dose of diamorphine, and ethical approval was also granted to vary the dose administered $(+0 / 10 / 20 \%)$ between sessions on a single-blind basis [34]. Changes in respiratory function, in this contrived overdose laboratory setting, included sometimes profound responses [34] (Fig. 4).

In the first graph, the baseline pre-dosing levels show a breathing rate of approximately 8 breaths per minute with no absences of breathing (apnoea). The red line shows the stable level of oxygen saturation (peripheral venous) at about $95 \%$. The green line shows the rise and fall of carbon dioxide, as expected, accumulating and then expelled with each exhalation.
In the second graph, we see the same measures recorded $5 \mathrm{~min}$ after intravenous administration of $100 \mathrm{mg}$ heroin (the patient's regular injectable dose). Its profound effect on respiratory function is striking, with occasional prolonged periods of complete apnoea lasting for $30 \mathrm{~s}$ or longer, with destabilization of carbon dioxide levels, and with oxygen saturation levels showing initial resilience followed by decline as the apnoea persists and continuing for half a minute beyond the resumption of breathing (presumably relating to the time-lag between oxygenation in the pulmonary vasculature vs. the peripheral venous system which was being measured). The third graph shows the unexpected finding that, even $1 \mathrm{~h}$ later, there was still abnormal breathing with apnoeic episodes, hypercapnia, and hypoxaemia. 


\section{The Search for Impact}

Deaths can be prevented if the overdose danger is recognized and if an observer is present, through rescue breathing whilst awaiting an ambulance. If naloxone is available and if the observer feels competent, then the option also exists to administer an interim dose of naloxone to reduce or reverse the opioid overdose and the associated respiratory depression (and hence the likelihood of fatal outcome).

From a medical perspective, "take-home naloxone" is simply technology transfer, the transfer of a technological procedure from an exclusively specialist arena to the situation where the crisis occurs. However, it is more than just the "technology" that needs to be transferred as it is also necessary for there to be acceptance that these formerly exclusively medical materials might properly be used by non-medical persons. There are thus parallels to equipping patients and families with emergency adrenaline/epinephrine (e.g., EpiPen ) in case of anaphylactic reactions, and also the training of family and the general public in cardiopulmonary resuscitation and cardiac defibrillators for emergency use by the general public. Each example has encountered challenges to wider implementation with, e.g., the slow history of portable and public cardiac defibrillators $[35,36]$, perhaps deriving from both professional and public uncertainty about the technology transfer, in contrast to dissemination of emergency medical procedures where the intervention is similarly lifesaving but does not require any medication or special equipment such as public training about the Heimlich manoeuvre when confronted with someone in danger of choking to death [37].

We first articulated the concept of take-home naloxone in a BMJ editorial in 1996 - "Heroin overdose: the case for take-home naloxone (home based supplies of naloxone would save lives)" [25]. This "manifesto" identified different members of the new intervention workforce, including those recently resuscitated who might be leaving the emergency department against medical advice, those reentering the community after a period of non-use such as on release from prison or after discharge from a treatment program, as well as all opioid users in treatment plus those attending needle and syringe exchange. In addition, the potential to pre-provide friends and family with naloxone for emergency administration was identified, and even the possibility that the legal status of naloxone might be changed to permit it to be sold over the counter by community pharmacies so as to reach a wider population of drug users. It is sobering that many of the necessary

Take-Home Naloxone and the Prevention of Heroin Overdose Deaths
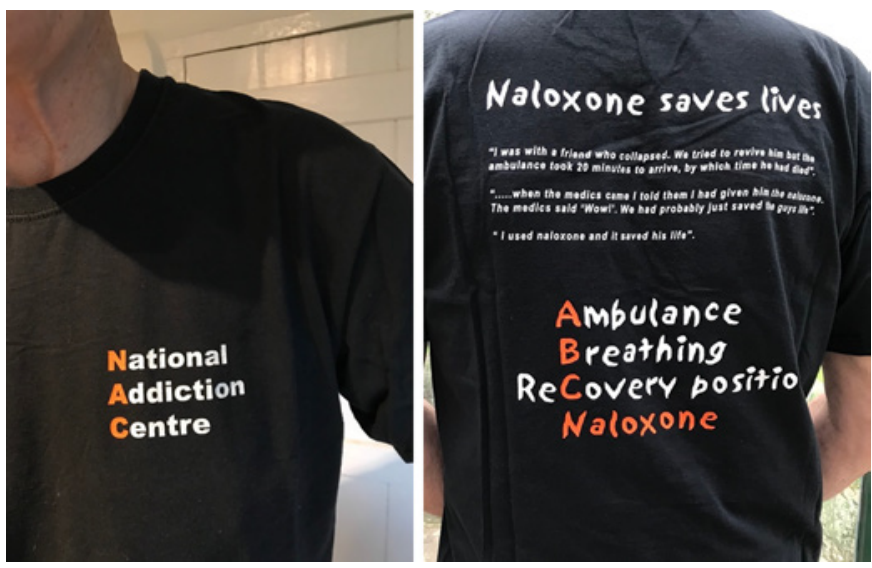

Fig. 5. Photo of "Naloxone saves lives" T-shirt (2005).

steps were described then, and yet still remain only patchily implemented. In the UK context, the series of reports from the UKs Advisory Council on the Misuse of Drugs (ACMD) document the broad acceptance of the legitimacy of teaching overdose training, and also the broad support for take-home naloxone - evident from its 2000 report [38] and subsequent considerations in 2016 [39] and 2022 (forthcoming).

In the remainder of this section, our search for evidence of impact finds variable evidence, with many descriptions of local and even national initiatives but a relative paucity of the strongly-designed intervention trials that would usually accompany a new treatment. Some important studies have now been done, but progress has been slow and patchy. A logical conclusion is that science needs to turn its attention to study of this interesting innovation.

Early UK and mainland European take-home naloxone provision was operational from 1998 onwards [40] at a very local level on the island of Jersey in the Channel Islands and also from a street agency in Berlin, and similarly in parts of London from 2001 onwards [41]. However, a bigger more strategic approach was clearly required (examples of initiatives described are ones with which the author is most familiar; others would choose different examples).

Larger scale planning in the UK occurred from 2005 onwards. With funding from the English National Treatment Agency (NTA), "training the trainers" was provided, in 2005, to support take-home naloxone provision via agencies across England [26]. This carried the branding "Naloxone saves lives" (Fig. 5). We provided training to 219 staff working in 6 diverse drug-treatment services op- 


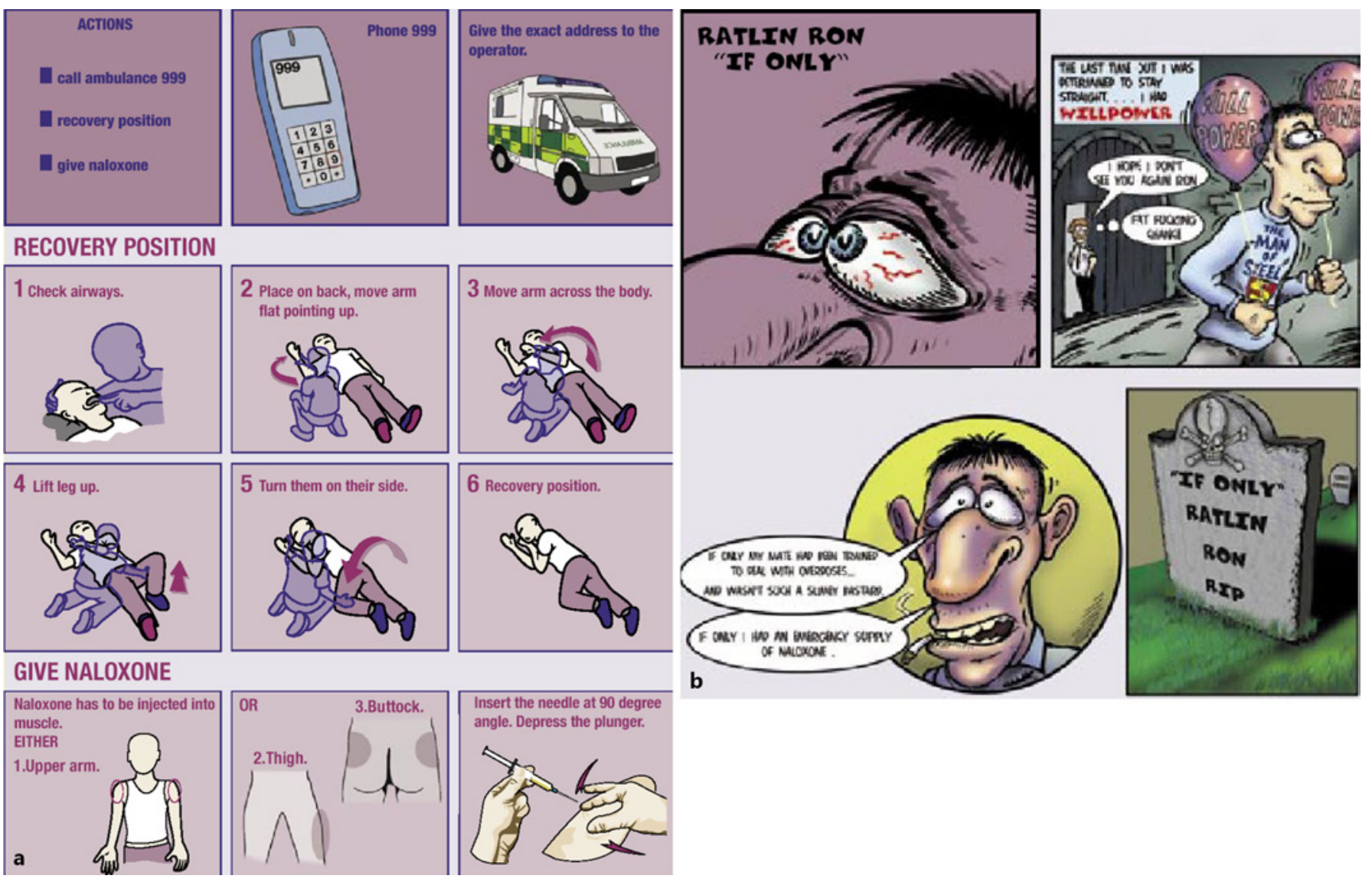

Fig. 6. a, b Leaflets/posters developed with exchange supplies (a) and lifeline (b).

erating, between them, 20 clinical services across England: from these treatment teams, 100 staff received training directly plus 119 via cascade, with overdose training plus naloxone provision (intramuscular) to 239 individuals attending treatment services $[26,42]$. We also developed leaflets/posters describing essential overdose management and the administration of naloxone - in both standard format and also in "alternative" cartoon format (Fig. 6). We also surveyed family support groups and realized they were a different potential intervention workforce and that they had received little or no support and little or no guidance about how to manage a potential future emergency overdose situation $[26,43]$. We also described the achievements and the considerable operational obstacles encountered [42]. Re-reading the recommendations from the reports to the NTA on this initiative (pages 10-11 of web-appendix) and in summary as online supplementary materials in the $B M J$ in 2006 [44], it can be seen that recommendations were made then, and yet are still only weakly implemented (Fig. 7).
Family members and carers were the focus of a subsequent initiative from the NTA, taking forward the recommendations from the naloxone carers survey [26] with delivery of the "NTA overdose and naloxone training program for families and carers" training initiative. Carers were, and still are, a widely overlooked and often ignored group, to whom naloxone is still only rarely provided.

An important step-change happened in Scotland in 2010 , when it became the first country in the world to announce a national programme of take-home naloxone [45]. In addition to provision from community treatment programs and needle and syringe exchange schemes, takehome naloxone was also provided to former-heroin-using prisoners on release $[46,47]$. Scotland also committed energy to data capture, thereby enabling valuable tracking of provision and the assessment of impact [45-49].

A similar national scheme was introduced in Wales at about the same time [50]. Comparing different countries within the UK, it is notable that no similar nationally coordinated scheme of take-home naloxone was initiated in 
Fig. 7. Recommended next steps, 2006 - to $B M J$ and National Treatment Agency.

\section{Good practice with take-home naloxone}

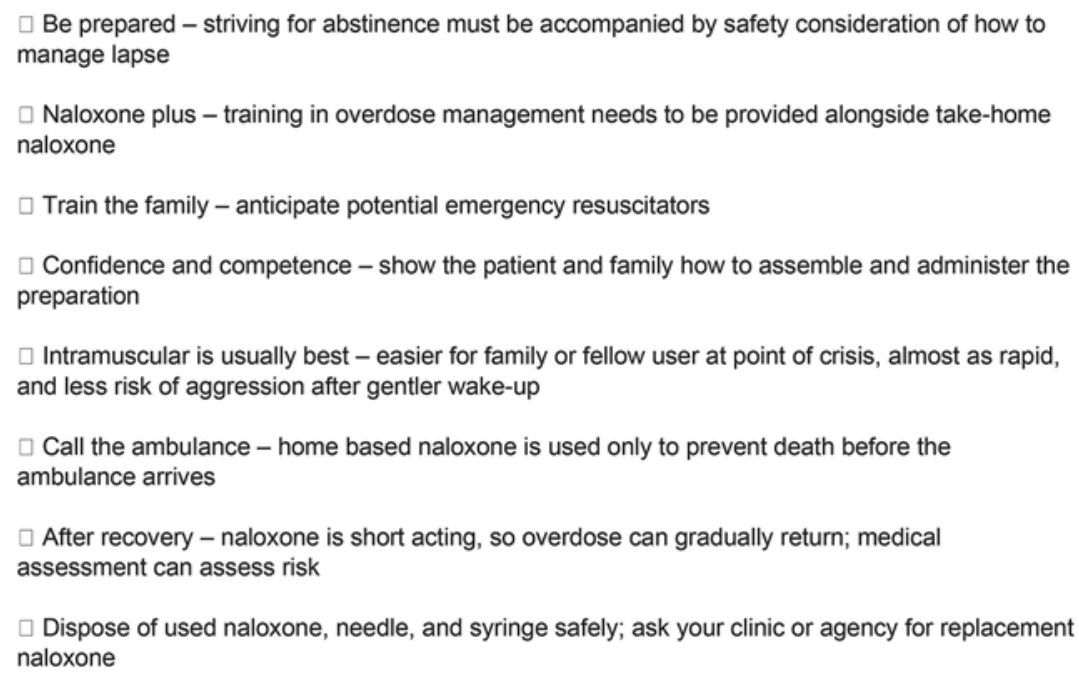

England. Provision of addiction treatment services in England is more devolved to local level: an advantage on occasions, but a disadvantage when introducing contentious innovation.

However, notwithstanding these important initiatives and the extensive reports of individual lives saved, it is also important for there to be scientific study of the impact of take-home naloxone at a population level. It is in this scientific space that there is need for more attention, and application of stronger scientific methods. Notable examples of strong science do exist, such as the interrupted time-series analysis across Massachusetts [30] reporting significantly reduced rate ratio of fatal overdose in areas with high or medium enrolment in take-home naloxone when compared with areas with no implementation, and also the study of the effectiveness of Scotland's programme of take-home naloxone to former-heroin-user prisoners on their release, with consistent reduced overdose deaths in the month post-release after the introduction of the naloxone scheme [51]. Bird and colleagues were able to calculate the necessary extent of provision of take-home naloxone kits, concluding that schemes needed to issue at least 9-20 times as many kits as the annual number of overdose deaths [52]. In addition, cost-effectiveness analyses have been undertaken in several countries and consistently find provision of take-home naloxone to be a cost-effective intervention [53-55].
Science must also be ready to respond to emerging public or professional concerns, to establish what validity they have, and the extent to which they are relevant. One example is the mooted possibility that the associated sense of safety may paradoxically lead to increased risky behaviour ("risk compensation"): little evidence of this theoretical risk has been found and specific examination of this possibility in a randomized trial found no such evidence [29]. A second example is the concern that excessive naloxone dosing could cause "over-antagonism" [56] with resulting hostility to the person resuscitating the victim alongside further drug-seeking to reverse the reversal: new studies between researchers in London, New York, and Melbourne [57-60] has explored this phenomenon and their implications for necessary revisions to policy and practice. A third recently identified concern is the reports of low carriage rates of take-home naloxone, a characteristic of possible importance if it leads to missed actions, and which seems to be very variable between settings ( $<10 \%$ in Scotland; $>40 \%$ in Norway $[61,62])$, with recent survey comparing different European countries finding considerable variability (forthcoming). The challenge is not only to ask simple questions but also to explore the meaning of carriage itself [63]. For more summary of the evidence base for take-home naloxone, the reader is also directed to publish reviews [64-67], although we must remember that the above-summarized limitations still need to be addressed. 


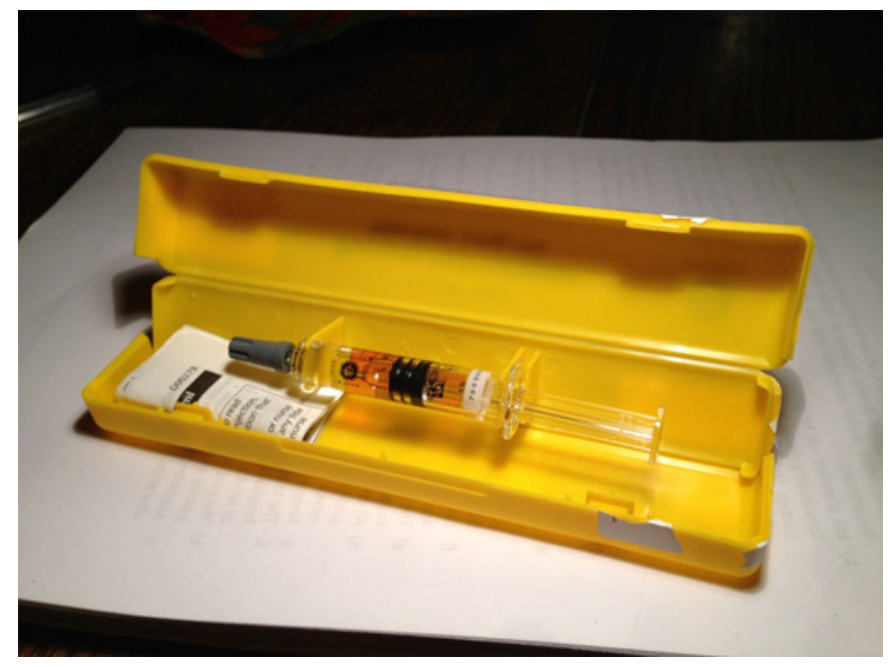

Fig. 8. The original 5-dose pre-filled naloxone syringe for accident and emergency and ambulance paramedics.

\section{The Search for Better Forms of Naloxone}

\section{Development of Better Injectable Naloxone}

Naloxone formulations clearly needed modification to be optimized for emergency administration by people not familiar with handling medicines. Back in 1996, when first seriously articulating the case for take-home naloxone [25], we were already identifying the need for modification and suggested a disposable pre-loaded syringe. By 1999, we were suggesting a ready-loaded syringe with needle attached and raised the possibility of future intranasal naloxone [68].

In early 2000s, a 5-dose pre-filled naloxone syringe (2 $\mathrm{mg} / 2 \mathrm{~mL}$ ) was brought to market by Martindale Pharma in the UK and subsequently across much of Europe and became the main product used by take-home naloxone schemes (Fig. 8). This resolved part of the challenge, although the risk existed that a needle might not be available at the time of future emergency. The risk also existed that, with five $0.4 \mathrm{mg}$ doses in the pre-filled syringe, an excessive dose might be given.

In Glasgow in the early 2010s [69], an adaptation was introduced in which the box containing the Martindale naloxone syringe was opened so that needles and basic instruction could be added, after which the box was closed and re-sealed, ready for distribution, and provision to injecting drug users.

In 2013, influenced by the Glasgow development, a new naloxone product, "Prenoxad," was brought to market by Martindale, an adaptation of their previous mul-

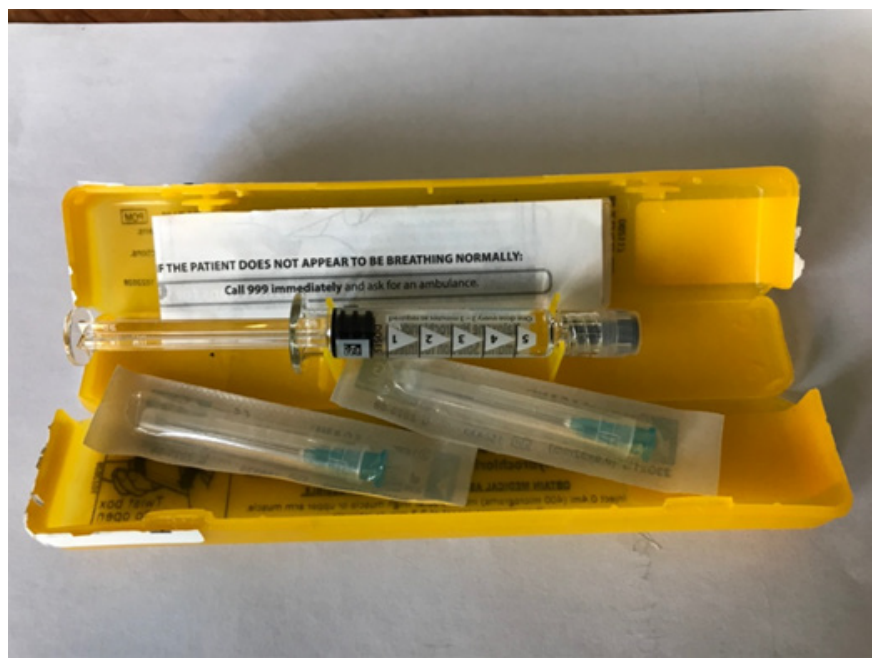

Fig. 9. The new adapted Martindale 5-dose pre-filled naloxone syringe for pre-provision to drug users and families (2013 onwards).

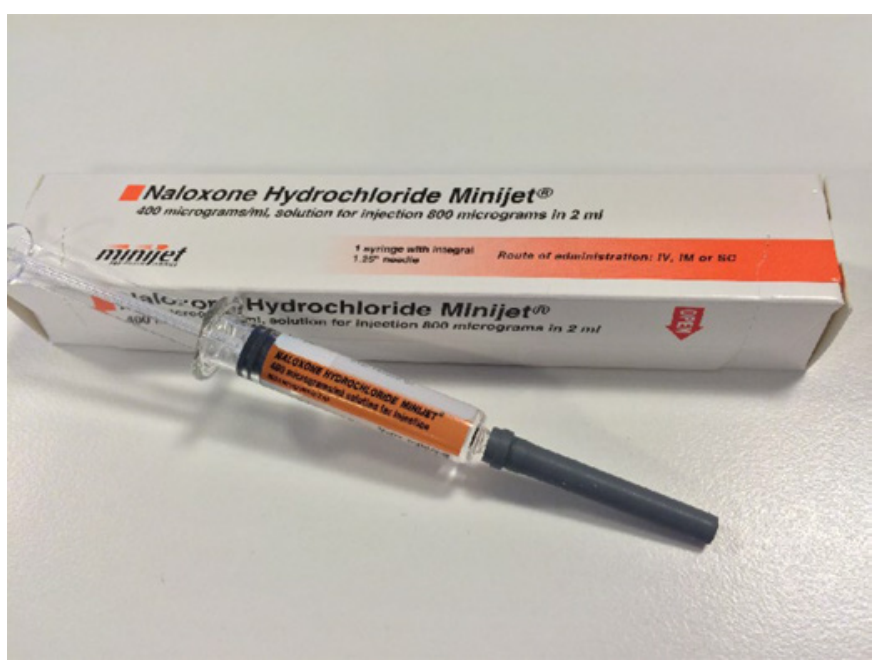

Fig. 10. A 2-dose pre-filled naloxone syringe with fixed attached needle (2015).

tidose pre-filled syringe (still $2 \mathrm{mg} / 2 \mathrm{~mL}$ ) although now with gradations on the barrel of the syringe to indicate the 5 doses $(0.4 \mathrm{mg}$ each), as well as the inclusion of needles plus instructions within the distinctive yellow box (Fig. 9).

A later similar product was developed and brought to market in 2015 by another manufacturer (UCB), this time with a stake needle and a 0.8 -mg dose (Fig. 10). However, this seems to have been abandoned by the manufacturer, presumably for commercial or strategic reasons. 
Fig. 11. Plasma levels of naloxone in healthy volunteers after naloxone administered by different routes (as reported in McDonald et al. [72]).

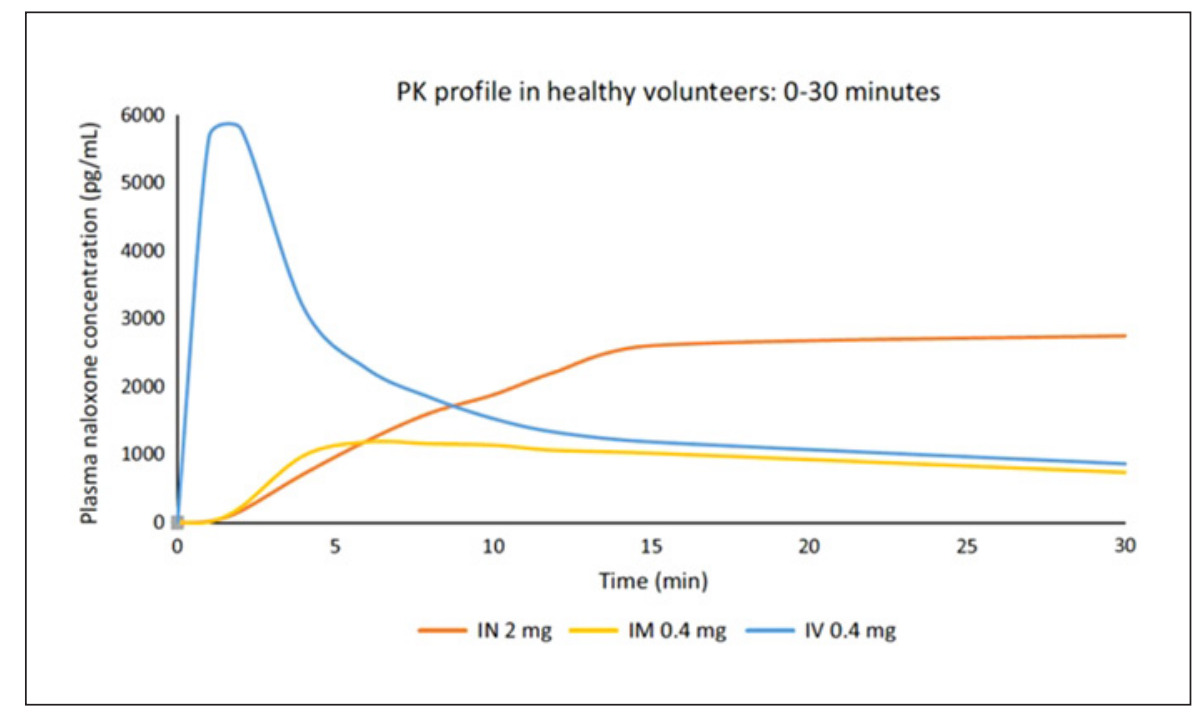

Development of Concentrated Naloxone Nasal Spray

Efforts to develop a purpose-built naloxone nasal spray required commitment from a pharmaceutical company. Early discussions with several companies resulted in initial interest, including registration of intellectual property, but did not reach the threshold of willingness to commit funds for necessary development work to bring a new product to market.

The engagement of the pharmaceutical industry was successfully kickstarted in the USA by a special FDA initiative [70]. In Europe, around 2015, one company (Mundipharma) decided to explore the feasibility of producing a concentrated naloxone nasal spray. We had identified that they already had available data from an earlier unpublished study of concentrated naloxone solution administered nasally, undertaken for different reasons. Working with scientists in the company, we examined these earlier pharmacokinetic data with a view to developing a concentrated naloxone nasal spray suitable for take-home naloxone schemes [71].

A decision was needed about the correct dose for a new concentrated naloxone nasal spray, suitable for introduction in Europe. With the re-discovered evidence indicating sufficiently rapid speed of onset and a relative bioavailability of about $40 \%$ [71], we concluded that a nasal spray which delivered a 2-mg dose was probably optimal since it might be considered as broadly equivalent to $0.4-$ $0.8 \mathrm{mg}$ intramuscularly. A consensus had also emerged that take-home naloxone products should be at least twin-pack formulations, thereby enabling crude dose titration.

Take-Home Naloxone and the Prevention of Heroin Overdose Deaths
Pharmacokinetic studies were conducted with healthy volunteers to ascertain speed of absorption and overall bioavailability, relative to a reference dose of $0.4 \mathrm{mg}$ intramuscularly (and a secondary intravenous reference dose of $0.4 \mathrm{mg}$ ) with 3 different possible doses of concentrated naloxone nasal spray ( $1 \mathrm{mg}, 2 \mathrm{mg}$, and $4 \mathrm{mg}$ ). Furthermore, in anticipation of adequate absorption from the $1 \mathrm{mg}$ or $2 \mathrm{mg}$ concentrations, we used a double dose of the $2 \mathrm{mg}$ concentration as the method of giving the 4 mg dose - which thereby allowed us to examine whether a double spray of the $2 \mathrm{mg}$ concentration would deliver a dose approximately twice that of a single spray. These data became the basis of the decision by the company (Mundipharma) to seek product licence approval for a 2-mg concentrated naloxone nasal spray (subsequently known as "Nyxoid" nasal spray), for which European product licence approval was granted by the European Medicines Agency (EMA) in September 2017 (and also similar approval in Australia in 2018). These pharmacokinetic data and associated analyses formed the basis of a collaborative academic publication [72] (Fig. 11).

These pharmacokinetic data allow consideration of the likely different resuscitating effect of the new concentrated naloxone nasal sprays. The different new nasal sprays all had very similar PK profiles. It had previously been noted that intravenous administration often provoked hostility or aggression and that many clinicians in emergency medicine preferred intramuscular naloxone which gave sufficiently prompt effect with much less likelihood of accompanying hostility. The report from the Vancouver ambulance service [73] had been influential, recommending "waking them gently" [74]. Scrutinizing

Eur Addict Res 2022;28:161-175 169 


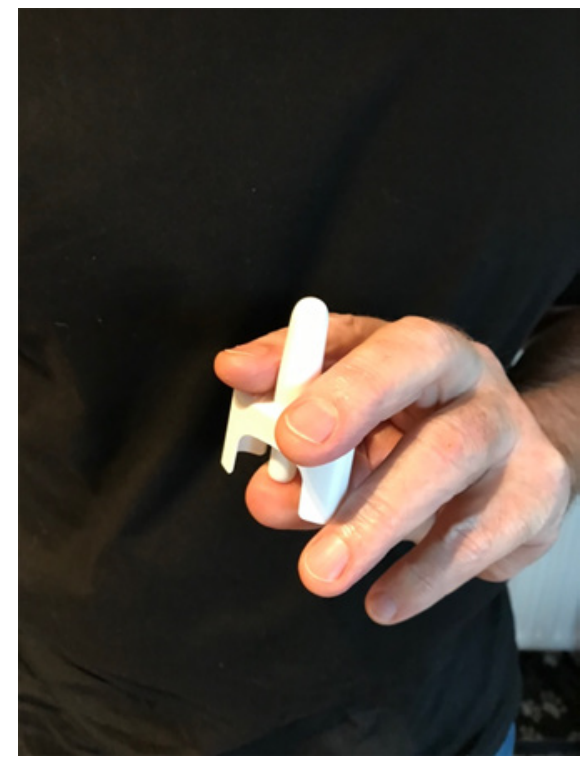

Fig. 12. The Aptar nasal spray device - the basis of all the new concentrated naloxone nasal sprays.

the PK data, it is the spike at the left-hand end of the PK curve from intravenous use that is likely associated with this provocation of hostility. Looking at the PK curve following intramuscular administration, it broadly tracks the same as the intravenous curve, apart from the absence of this initial spike. The intramuscular PK curve has generally been accepted as the relevant reference curve when studying the new nasal formulations.

Taking the intramuscular $0.4 \mathrm{mg}$ curve as comparator, the $1 \mathrm{mg}$ concentrated naloxone nasal spray seems to deliver comparable naloxone, apart from the first 5-10 $\mathrm{min}$ when it is significantly below the intramuscular curve. However, the first 5-10 min are clinically critical. At the other end of the dose range, the $4 \mathrm{mg}$ concentrated naloxone nasal spray produces a more rapid increase in blood levels during the first 5-10 $\mathrm{min}$, but then displays "overshoot." In between these 2 doses, the 2 mg naloxone nasal spray produces speed of onset comparable to intramuscular $0.4 \mathrm{mg}$ naloxone although with subsequent "plateau" plasma levels well in excess of the intramuscular reference but proportionately less than seen with the $4 \mathrm{mg}$ dose. A final PK observation was that, with the double dose of the $2 \mathrm{mg}$ spray, plasma levels were proportionally greater, suggesting two $2 \mathrm{mg}$ sprays are comparable to a single $4 \mathrm{mg}$ spray [72].

It is interesting to compare the 4 new nasal sprays for which approval has been granted in different countries (for fuller review [64]). All 4 new naloxone nasal sprays use the same delivery device, the Aptar single-dose nasal spray (Fig. 12): Narcan nasal spray (4 mg) in the USA and Canada [75], Nyxoid nasal spray (2 mg) in Europe and Australia [72], Ventizolve nasal spray (1.4 mg) in Norway [76-78], and Nalscue (1 mg) in France (n.b. to improve understanding, we describe doses according to their weight in the salt form, even though regulatory approvals differ, with some reporting naloxone according to the salt form and others as base). The striking conclusion is the similarity of performance of the 4 new nasal sprays, notwithstanding their different doses, with speed of onset likely satisfactory in most circumstances and with overall bioavailability (relative to intramuscular) of approx 40$50 \%$, and with good maintenance of plasma levels over the decay period - a reassuring picture for the new nasal sprays.

\section{Challenges Still to Be Addressed}

In this final section, we identified 7 areas where much more still needs to be done.

\section{Extent of Provision of Take-Home Naloxone}

Provision of take-home naloxone remains patchy, even in communities, cities, or countries which have led the way. Institutional inertia abounds, and the novelty of the concept of take-home naloxone adds to the inertia. There are also important parts of the treatment and rehabilitation sector which do not recognize the importance of overdose awareness, training in emergency intervention, and naloxone administration, e.g., many residential rehabilitation and detoxification facilities as well as 12step and other mutual aid support groups [79-81]. In the $\mathrm{UK}$, it is 25 years since we first called for the provision of take-home naloxone, to be provided by drug-treatment services and other agencies including prison, residential and needle and syringe exchange schemes. Surely the time has come for offer of take-home naloxone to become a care standard, a required element of comprehensive care.

\section{Uncertainty about Naloxone Dose}

Naloxone dose needs to be sufficient to reverse the opioid overdose that might cause death. But it is also important to avoid giving excess naloxone which might precipitate acute opioid withdrawal which, in addition to causing unnecessary distress and risk of hostility, might trigger further drug-seeking to reverse the naloxone-trig- 
gered reversal $[56,59,82]$. We also need to establish if dose titration can effectively be taught to this new intervention workforce: the principles are simple, as is the practice, requiring the administration of an initial dose, observation of its effect over the next few minutes, then a decision whether a repeat dose is required. The provision of naloxone in twin-pack formats, as is currently universal practice, makes simple dose titration feasible.

\section{Preserving the Positive Reputation of Take-Home \\ Naloxone}

The prevailing positive opinion about naloxone by drug users themselves should not be taken for granted. Our own societal decisions will also influence stigma and implementation barriers [58]. In the past, naloxone has been viewed by drug users with resentment, a drug given to punish them or to reveal hidden dependence. Through all of this time, it has saved lives by reversing heroin overdose and has the potential to do so more extensively if it is pre-placed more effectively. But this positive reputation is not indestructible: clumsy administration and hostile attitudes could easily undo much of the good work that has been achieved. We must proceed boldly, but also with sensitive consultation and engagement with the relevant target populations.

\section{Realistic Portability of Take-Home Naloxone}

Like condoms, EpiPens, and defibrillators, naloxone can protect against unintended consequences, but only if present and used at the critical time of need. Naloxone can unquestionably prevent overdose deaths that are only minutes away, but only if it is at hand. Evidence from recent surveys $[61,83]$ finds extremely low carriage rates. This needs to trigger initiatives of 2 sorts: firstly, behavioural interventions to improve naloxone confidence and competence, and secondly, we need new naloxone products which fit comfortably in a wallet or pocket (the "Levis Jeans test").

\section{The Cost of Naloxone}

Around the world, there are absurd differences in the price of naloxone products. At one end of the spectrum, we have ampoules available for less than USD 1 per ampoule, whilst at the other end of the spectrum we have auto-injectors at several thousand US dollars per device [84]. It is hard to see the justification for these differences, since the medication in the devices is the same. Not only do these price differences offend, but they also do harm because they interfere with efforts to increase naloxone availability so that it is there, at time of future need.

Take-Home Naloxone and the Prevention of Heroin Overdose Deaths

\section{The Research Study of Overdose}

Given the global burden and the public concern about opioid overdose, it is remarkable how little clinical laboratory research study has been undertaken in order to understand opioid overdose more fully. Our own work (summarized above) has shown the feasibility of overdose study in a safe clinical setting to enable study of underlying mechanisms and influences. With cautious planning (preferably with discussion with putative volunteers), it might also be possible to test overdose reversal. Such an approach should also include study of newer opiates such as fentanyl, and also the influence of co-consumed benzodiazepines or alcohol. Studies in an "overdose laboratory" are long overdue.

Harnessing Future Technologies, Including Wearables

With imagination and early exploration, we can envisage a time when wearable devices detect overdose, or its imminence, just as it is already possible for wearable devices to send alerts after detecting a fall or abnormal heart rhythms [85]. There are many directions in which this might lead. One avenue might be the early alert of an escalation in risk behaviour and the potential value of attention from partner, family, or therapist. Another avenue might involve not only the detection of an acute overdose event but possibly even the delivery of corrective measures as well as summoning help. Even if not yet achievable, we must explore such possibilities, just as is done by clinicians, researchers, and policymakers in other areas of healthcare and public policy.

\section{Overall Conclusion}

Over recent decades, we have made important advances in our understanding of why, when and how heroin overdose deaths occur. In addition to the wider rehabilitative benefits, treatment with opioid substitution treatments such as methadone and buprenorphine confers a protective effect against overdose death $[5-7,10,11,13]$, with 5-fold reduced mortality when in treatment. Additionally, many specialist treatments also confer life-saving benefit, especially as alternative responses by society, such as leaving individuals languishing in homelessness or prison or abandonment outside treatment, are associated with increased mortality.

Moving specifically to naloxone and overdose emergency, we now know there are clusterings of deaths on release from prison and after leaving treatment or rehabilitation, and we realize the aggravating influence of coadministration of other sedative drugs such as benzodi- 
azepines or alcohol. We also now mobilize public response by teaching the general public, including family members, partners and peers and also drug users themselves, how they can intervene to prevent overdose death in the interval between identifying an overdose emergency and the arrival of medical services on the scene. Takehome naloxone schemes are the embodiment of this approach and stand as a major global harm reduction response. The component parts of take-home naloxone still need to be improved (better naloxone products, better training aids, revised legislation, explicit funding support), and must be accompanied by the range and quality of research endeavour that we would expect to see for other new life-saving interventions.

To conclude, let us return to the quote from John Donne "Any man's death diminishes me because I am involved in mankind." We can be proud of what we have achieved, but we must also be humble about how much more we still need to do.

\section{Acknowledgments}

I am grateful to European Federation of Addiction Societies (EUFAS) and to European Addiction Research for the invitation to prepare this article based on the talk given at the LxAddiction conference in Lisbon in October 2019 on the occasion of receipt of the 2019 European Addiction Research Award. I am also grateful to the various individuals from all walks of life who have helped me in a personal journey of understanding and discovery as we have conceived and realized the potential of take-home naloxone, including individuals with personal histories of substance use, their family members and friends, as well as those working in treatment, research and policy settings. I also acknowledge the contribution of colleagues working directly with me on past and current naloxone and overdose research studies. Finally, I am grateful for the continued assistance from Margarita Bela for patiently supporting me through manuscript preparation, reference searches, and seemingly endless revisions.

\section{Statement of Ethics}

All research described in this article has been considered and approved by the appropriate Ethics Committees and has been reported in this way in the original publications. The preparation of this article, and of the lecture at the LxAddictions conference associated with award of the 2019 EUFAS/EAR award, did not require specific additional ethics approval.

\section{Conflict of Interest Statement}

J.S. is a researcher and clinician who has an active interest in the potential of take-home naloxone and has been an advocate for its further development and introduction, alongside study of its application, and who, through his university, has worked and currently works with various government departments and also with pharmaceutical companies to identify new or improved treatments. Connected to this work, his employer (King's College London) has received grants, travel costs, and/or consultancy payments from companies including, past 3 years, Mundipharma, Camurus, Molteni, Accord and trial medication supply from Camurus. J.S. has also had discussions with various companies about technologies as well as medications potentially applicable in the treatment of addictions and related problems. For a fuller account, see J.S.'s web-page at http://www.kcl.ac.uk/ioppn/depts/addictions/people/hod.aspx.

His employer (King's College London) registered intellectual property on a buccal naloxone formulation, naming J.S. and colleagues, and he was earlier named in a patent registration by a pharmaceutical company regarding concentrated nasal naloxone spray. J.S. is currently leading a new international study (NalPORS) to track prospectively the overdose resuscitation experiences of a large cohort of individuals to whom a pre-supply of different forms of take-home naloxone has been provided (study funded by Mundipharma). J.S. and colleagues have also worked as consultants for the United Nations Office on Drugs and Crime, supporting them with a project introducing take-home naloxone to 4 central and western Asian countries (leading to the development of the S-O-S Initiative) as well as contributing to local takehome naloxone schemes. J.S. works (or has worked) with various drug policy organizations and advisory bodies including the UK Drug Policy Commission, the Society for the Study of Addiction (SSA), and the European Monitoring Centre for Drugs and Drug Addiction.

\section{Funding Sources}

No funding support was sought for this article. Individual studies referred to in this article may have received grant funding or other support and the reader is referred to the original articles for any funding sources relevant to these separate publications. J.S.s research is supported by the National Institute for Health Research (NIHR) Biomedical Research Centre for Mental Health at South London and Maudsley NHS Foundation Trust and King's College London. J.S. is an NIHR Senior Investigator.

\section{Author Contributions}

The author is a sole author to this article, and the views expressed are entirely his own.

\section{Data Availability Statement}

This article considers evidence already published (in European Addiction Research and elsewhere) and does not present new data. Enquiries about data access should be directed to the authors of the original publications. 


\section{References}

1 CDC. Opioid data analysis and resources. Centers for Disease Control and Prevention; 2020. Available from: https://www.cdc.gov/ drugoverdose/data/analysis.html.

2 van Amsterdam J, van den Brink W, Pierce M. Explaining the differences in opioid overdose deaths between Scotland and England/Wales: implications for European opioid policies. Eur Addict Res. 2021;27:399-412.

3 NICE. Methadone and buprenorphine for the management of opioid dependence. 2007. Available from: https://www.nice.org.uk/ guidance/ta114/resources/methadone-andbuprenorphine-for-the-management-of-opioid-dependence-pdf-82598072878789.

4 Connock M, Juarez-Garcia A, Jowett S, Frew E, Liu Z, Taylor RJ, et al. Methadone and buprenorphine for the management of opioid dependence: a systematic review and economic evaluation. Health Technol Assess. 2007;11(9):1-171.

5 Mattick RP, Breen C, Kimber J, Davoli M. Methadone maintenance therapy versus no opioid replacement therapy for opioid dependence. Cochrane Database Syst Rev. 2009; 2009(3):CD002209.

6 Mattick RP, Kimber J, Breen C, Davoli M. Buprenorphine maintenance versus placebo or methadone maintenance for opioid dependence. Cochrane Database Syst Rev. 2004;(3): CD002207.

7 Strang J, Volkow ND, Degenhardt L, Hickman M, Johnson K, Koob GF, et al. Opioid use disorder. Nat Rev Dis Primers. 2020;6(1):3.

8 Cornish R, Macleod J, Strang J, Vickerman P, Hickman M. Risk of death during and after opiate substitution treatment in primary care: prospective observational study in UK general practice research database. BMJ. 2010; 341:c5475.

9 Macleod J, Steer C, Tilling K, Cornish R, Marsden J, Millar T, et al. Prescription of benzodiazepines, $\mathrm{z}$-drugs, and gabapentinoids and mortality risk in people receiving opioid agonist treatment: observational study based on the UK Clinical Practice Research Datalink and Office for National Statistics death records. PLoS Med. 2019;16(11):e1002965.

10 Hickman M, Steer C, Tilling K, Lim AG, Marsden J, Millar T, et al. The impact of buprenorphine and methadone on mortality: a primary care cohort study in the United Kingdom. Addiction. 2018;113(8):1461-76.

11 Amato L, Davoli M, Perucci CA, Ferri M, Faggiano F, Mattick RP. An overview of systematic reviews of the effectiveness of opiate maintenance therapies: available evidence to inform clinical practice and research. J Subst Abuse Treat. 2005;28(4):321-9.

12 Faggiano F, Vigna-Taglianti F, Versino E, Lemma P. Methadone maintenance at different dosages for opioid dependence. Cochrane Database Syst Rev. 2003;(3):CD002208.
13 Faggiano F, Vigna-Taglianti FD, Versino E, Zambon A, Borraccino A, Lemma P. Schoolbased prevention for illicit drugs use: a systematic review. Prev Med. 2008;46(5):385-96.

14 Mattick RP, Kimber J, Breen C, Davoli M. Buprenorphine maintenance versus placebo or methadone maintenance for opioid dependence. Cochrane Database Syst Rev. 2004;(3): CD002207.

15 Farrell M, Marsden J. Acute risk of drug-related death among newly released prisoners in England and Wales. Addiction. 2008;103(2): 251-5.

16 Merrall EL, Kariminia A, Binswanger IA, Hobbs MS, Farrell M, Marsden J, et al. Metaanalysis of drug-related deaths soon after release from prison. Addiction. 2010;105(9): 1545-54.

17 Strang J, McCambridge J, Best D, Beswick T, Bearn J, Rees S, et al. Loss of tolerance and overdose mortality after inpatient opiate detoxification: follow up study. BMJ. 2003; 326(7396):959-60.

18 Merrall EL, Bird SM, Hutchinson SJ. A record-linkage study of drug-related death and suicide after hospital discharge among drugtreatment clients in Scotland, 1996-2006. Addiction. 2013;108(2):377-84.

19 White SR, Bird SM, Merrall EL, Hutchinson SJ. Drugs-related death soon after hospitaldischarge among drug treatment clients in Scotland: record linkage, validation, and investigation of risk-factors. PLoS One. 2015; 10(11):e0141073.

20 Singleton N, Pendry E, Taylor C, Farrell M, Marsden J. Drug-related mortality among newly released prisoners. London: Home Office Research, Development and Statistics Directorate; 2003. Report No.: 187.

21 Powis B, Strang J, Griffiths P, Taylor C, Williamson S, Fountain J, et al. Self-reported overdose among injecting drug users in London: extent and nature of the problem. Addiction. 1999;94(4):471-8.

22 Strang J, Powis B, Best D, Vingoe L, Griffiths $\mathrm{P}$, Taylor C, et al. Preventing opiate overdose fatalities with take-home naloxone: prelaunch study of possible impact and acceptability. Addiction. 1999;94(2):199-204.

23 Strang J, Best D, Man L, Noble A, Gossop M. Peer-initiated overdose resuscitation: fellow drug users could be mobilised to implement resuscitation. Int J Drug Policy. 2000;11(6): 437-45.

24 Best D, Gossop M, Man LH, Stillwell G, Coomber R, Strang J. Peer overdose resuscitation: multiple intervention strategies and time to response by drug users who witness overdose. Drug Alcohol Rev. 2002;21(3):26974.

25 Strang J, Darke S, Hall W, Farrell M, Ali R. Heroin overdose: the case for take-home naloxone. BMJ. 1996;312(7044):1435-6.
26 Strang J, Manning V, Mayet S, Ridge G, Best $D$, Sheridan J. Does prescribing for opiate addiction change after national guidelines? Methadone and buprenorphine prescribing to opiate addicts by general practitioners and hospital doctors in England, 1995-2005. Addiction. 2007;102(5):761-70.

27 Williams AV, Marsden J, Strang J. Training family members to manage heroin overdose and administer naloxone: randomized trial of effects on knowledge and attitudes. Addiction. 2014;109(2):250-9.

28 Strang J, Bird SM, Parmar MK. Take-home emergency naloxone to prevent heroin overdose deaths after prison release: rationale and practicalities for the N-ALIVE randomized trial. J Urban Health. 2013;90(5):983-96.

29 Parmar MK, Strang J, Choo L, Meade AM, Bird SM. Randomized controlled pilot trial of naloxone-on-release to prevent post-prison opioid overdose deaths. Addiction. 2017; 112(3):502-15.

30 Walley AY, Xuan Z, Hackman HH, Quinn E, Doe-Simkins M, Sorensen-Alawad A, et al. Opioid overdose rates and implementation of overdose education and nasal naloxone distribution in Massachusetts: interrupted time series analysis. BMJ. 2013;346:f174.

31 Campbell DN. OD: naloxone and the politics of overdose. 1st edn. MIT Press; 2020 Apr 3.

32 Jolley CJ, Bell J, Rafferty GF, Moxham J, Strang J. Understanding heroin overdose: a study of the acute respiratory depressant effects of injected pharmaceutical heroin. PLoS One. 2015;10(10):e0140995.

33 Strang J, Gossop M. Heroin addiction and the British system. Routledge; 2004.

34 Tas B, Jolley CJ, Kalk NJ, van der Waal R, Bell J, Strang J. Heroin-induced respiratory depression and the influence of dose variation: within-subject between-session changes following dose reduction. Addiction. 2020; 115(10):1954-9.

35 Pantridge JF, Geddes JS. A mobile intensivecare unit in the management of myocardial infarction. Lancet. 1967;2(7510):271-3.

36 Pantridge F. Wikipedia, the free encyclopedia. 2021. Available from: https:// en.wikipedia.org/w/index.php?title=Frank Pantridge\&oldid=1020395731.

37 Heimlich HJ, Patrick EA. The Heimlich maneuver. Best technique for saving any choking victim's life. Postgrad Med. 1990;87(6):38-53.

38 ACMD. Reducing drug related deaths: a report by the Advisory Council on the Misuse of Drugs. 2000.

39 Advisory Council on the Misuse of Drugs. Reducing opioid-related deaths in the UK. 2016. Available from: https://www.gov.uk/government/publications/reducing-opioid-relateddeaths-in-the-uk.

40 Dettmer K, Saunders B, Strang J. Take home naloxone and the prevention of deaths from opiate overdose: two pilot schemes. BMJ. 2001;322(7291):895-6. 
41 Strang J. Letter - BMJ response - author's reply. BMJ. 2001.

42 Mayet S, Manning V, Williams A, Loaring J, Strang J. Impact of training for healthcare professionals on how to manage an opioid overdose with naloxone: effective, but dissemination is challenging. Int J Drug Policy. 2011;22(1):9-15.

43 Strang J, Manning V, Mayet S, Titherington E, Offor L, Semmler C, et al. Family carers and the prevention of heroin overdose deaths: unmet training need and overlooked intervention opportunity of resuscitation training and supply of naloxone. Drugs (Abingdon Engl). 2008;15(2):211-8.

44 Strang J, Kelleher M, Best D, Mayet S, Manning V. Emergency naloxone for heroin overdose. BMJ. 2006;333(7569):614-5.

45 Bird SM, McAuley A. Scotland's national naloxone programme. Lancet. 2019;393(10169): $316-8$.

46 Horsburgh K, McAuley A. Scotland's national naloxone program: the prison experience. Drug Alcohol Rev. 2018;37(4):454-6.

47 Bird SM, McAuley A, Munro A, Hutchinson SJ, Taylor A. Prison-based prescriptions aid Scotland's national naloxone programme. Lancet. 2017;389(10073):1005-6.

48 Bird SM, McAuley A, Perry S, Hunter C. Effectiveness of Scotland's national naloxone programme: response to letter to editor. Addiction. 2016;111(7):1304-6.

49 McAuley A, Bouttell J, Barnsdale L, Mackay D, Lewsey J, Hunter C, et al. Evaluating the impact of a national naloxone programme on ambulance attendance at overdose incidents: a controlled time-series analysis. Addiction. 2017;112(2):301-8.

50 Bennett T, Holloway K. The impact of takehome naloxone distribution and training on opiate overdose knowledge and response: an evaluation of the THN project in Wales. Drugs. 2012;19(4):320-8.

51 Bird SM, McAuley A, Perry S, Hunter C. Effectiveness of Scotland's national naloxone programme for reducing opioid-related deaths: a before (2006-10) versus after (201113) comparison. Addiction. 2016;111(5):88391.

52 Bird SM, Parmar MK, Strang J. Take-home naloxone to prevent fatalities from opiateoverdose: protocol for Scotland's public health policy evaluation, and a new measure to assess impact. Drugs. 2015;22(1):66-76.

53 Coffin PO, Sullivan SD. Cost-effectiveness of distributing naloxone to heroin users for lay overdose reversal in Russian cities. J Med Econ. 2013;16(8):1051-60.

54 Langham S, Wright A, Kenworthy J, Grieve R, Dunlop WCN. Cost-effectiveness of takehome naloxone for the prevention of overdose fatalities among heroin users in the United Kingdom. Value Health. 2018;21(4):40715.
55 Acharya M, Chopra D, Hayes CJ, Teeter B, Martin BC. Cost-effectiveness of intranasal naloxone distribution to high-risk prescription opioid users. Value Health. 2020;23(4): 451-60.

56 Neale J, Strang J. Naloxone - does over-antagonism matter? Evidence of iatrogenic harm after emergency treatment of heroin/opioid overdose. Addiction. 2015;110(10):1644-52.

57 Neale J, Brown C, Campbell ANC, Jones JD, Metz VE, Strang J, et al. How competent are people who use opioids at responding to overdoses? Qualitative analyses of actions and decisions taken during overdose emergencies. Addiction. 2019;114(4):708-18.

58 Fomiatti R, Farrugia A, Fraser S, Dwyer R, Neale J, Strang J. Addiction stigma and the production of impediments to take-home naloxone uptake. Health. 2020.

59 Neale J, Kalk NJ, Parkin S, Brown C, Brandt L, Campbell ANC, et al. Factors associated with withdrawal symptoms and anger among people resuscitated from an opioid overdose by take-home naloxone: exploratory mixed methods analysis. J Subst Abuse Treat. 2020; 117:108099

60 Parkin S, Neale J, Brown C, Jones JD, Brandt $\mathrm{L}$, Castillo F, et al. A qualitative study of repeat naloxone administrations during opioid overdose intervention by people who use opioids in New York City. Int J Drug Policy. 2021;87:102968.

61 McAuley A, Munro A, Bird SM, Hutchinson SJ, Goldberg DJ, Taylor A. Engagement in a national naloxone programme among people who inject drugs. Drug Alcohol Depend. 2016;162:236-40.

62 Madah-Amiri D, Gjersing L, Clausen T. Naloxone distribution and possession following a large-scale naloxone programme. Addiction. 2019;114(1):92-100.

63 McDonald R, Parkin S, Eide D, Neale J, Clausen T, Metrebian N, et al. Rethinking "carriage" of take-home naloxone. Int J Drug Policy. 2021;95:103253.

64 Strang J, McDonald R, Campbell G, Degenhardt L, Nielsen S, Ritter A, et al. Take-home naloxone for the emergency interim management of opioid overdose: the public health application of an emergency medicine. Drugs. 2019;79(13):1395-418.

65 McDonald R, Strang J. Are take-home naloxone programmes effective? Systematic review utilizing application of the Bradford Hill criteria. Addiction. 2016;111(7):1177-87.

66 Olsen A, McDonald D, Lenton S, Dietze PM. Assessing causality in drug policy analyses: how useful are the Bradford Hill criteria in analysing take-home naloxone programs? Drug Alcohol Rev. 2018;37(4):499-501.

67 Moustaqim-Barrette A, Dhillon D, Ng J, Sundvick K, Ali F, Elton-Marshall T, et al. Takehome naloxone programs for suspected opioid overdose in community settings: a scoping umbrella review. BMC Public Health. 2021;21(1):597.
68 Strang J. Take-home naloxone: the next steps (response by author). Addiction. 1999.

69 Perry S, Mackintosh S. Glasgow naloxone programm - instructor manual. Scottish Drugs Forum/NHS Greater Glasgow and Clyde/Glasgow Addiction Service; 2007.

70 Hertz S. Naloxone for outpatient use: data required to support an NDA. Silver Spring, MD; 2012. Available from: http://www.fda.gov/ downloads / D r ugs / N ews Event s / UCM300874.pdf Accessed 2019 Jun 17.

71 Mundin G, McDonald R, Smith K, Harris S, Strang J. Pharmacokinetics of concentrated naloxone nasal spray over first 30 minutes post-dosing: analysis of suitability for opioid overdose reversal. Addiction. 2017;112(9): 1647-52.

72 McDonald R, Lorch U, Woodward J, Bosse B, Dooner H, Mundin G, et al. Pharmacokinetics of concentrated naloxone nasal spray for opioid overdose reversal: phase I healthy volunteer study. Addiction. 2018;113(3):484-93.

73 Wanger K, Brough L, Macmillan I, Goulding J, MacPhail I, Christenson JM. Intravenous vs subcutaneous naloxone for out-of-hospital management of presumed opioid overdose. Acad Emerg Med. 1998;5(4):293-9.

74 Horowitz Z. Subcutaneous naloxone: a less rude awakening? Acad Emerg Med. 1998; 5(4):283-5.

75 Krieter P, Chiang N, Gyaw S, Skolnick P, Crystal R, Keegan F, et al. Pharmacokinetic properties and human use characteristics of an FDA-approved intranasal naloxone product for the treatment of opioid overdose. J Clin Pharmacol. 2016;56(10):1243-53.

76 Tylleskar I, Skulberg AK, Nilsen T, Skarra S, Jansook P, Dale O. Pharmacokinetics of a new, nasal formulation of naloxone. Eur J Clin Pharmacol. 2017;73(5):555-62.

77 Skulberg AK, Tylleskar I, Nilsen T, Skarra S, Salvesen $\varnothing$, Sand T, et al. Pharmacokinetics and -dynamics of intramuscular and intranasal naloxone: an explorative study in healthy volunteers. Eur J Clin Pharmacol. 2018;74(7): 873-83.

78 Skulberg AK, Åsberg A, Khiabani HZ, Røstad $\mathrm{H}$, Tylleskar I, Dale O. Pharmacokinetics of a novel, approved, $1.4-\mathrm{mg}$ intranasal naloxone formulation for reversal of opioid overdose-a randomized controlled trial. Addiction. 2019; 114(5):859-67.

79 Bowles JM, Smith LR, Mittal ML, Harding RW, Copulsky E, Hennessy G, et al. "I wanted to close the chapter completely ... and I feel like that [carrying naloxone] would keep it open a little bit": refusal to carry naloxone among newly-abstinent opioid users and 12step identity. Int J Drug Policy. 2021;94: 103200.

80 Bennett AS, Freeman R, Des Jarlais DC, Aronson ID. Reasons people who use opioids do not accept or carry no-cost naloxone: qualitative interview study. JMIR Form Res. 2020; 4(12):e22411. 
81 McDonald R, Hills R, Hunter C, Horsburgh K, McAuley A, Mundt-Leach R, et al. Reducing deaths from opiate overdose: take-homenaloxone. In: Mistral W, editor. Integrated approaches to drug \& alcohol problems: action on addiction. 2016.

82 Parkin S, Neale J, Brown C, Campbell ANC, Castillo F, Jones JD, et al. Opioid overdose reversals using naloxone in New York City by people who use opioids: implications for public health and overdose harm reduction approaches from a qualitative study. Int J Drug Policy. 2020;79:102751.
83 Breidahl S, McDonald R, Sefranek M, Kelleher M, Eastaway J, Bhunnoo S, et al. Attitudes to naloxone intranasal spray in an inner London community of opioid-users: SSA poster. 2019. Available from: https://www.addictionssa.org/images/uploads/BreidahlSH_Attitudes_To_Naloxone_Intranasal_Spray_ Poster_Nov_18.pdf.
84 CBS News. Evzio: the overdose-reversal drug with a $\$ 4000+$ price tag. 2018. Available from: https: //www.cbsnews.com/news/evzio-theopioid-overdose-reversal-drug-naloxonewith-a-4000-price-tag-60-minutes/.

85 Raja JM, Elsakr C, Roman S, Cave B, PourGhaz I, Nanda A, et al. Apple watch, wearables, and heart rhythm: where do we stand? Ann Transl Med. 2019;7(17):417. 